\title{
Impact of the daily meal pattern on energy balance'
}

\author{
By France Bellisle
}

INRA (National Institute of Agronomy), Paris, France

Abstract

The daily distribution of food intake can influence the regulation of energy balance and, in consequence, the control of body weight. Two aspects of this question must be considered: the daily number of eating occasions and their temporal distribution. Since the 1960s, epidemiological studies have reported an inverse relationship between frequency of eating and body weight, suggesting that a "nibbling" pattern could help to prevent obesity. This notion has later been put into question by the recognition of a high level of dietary underreporting in overweight individuals. In addition, no difference in total daily energy expenditure has been documented as a function of daily meal number. Weight loss is not facilitated by high meal frequency. Snacking in obese subjects is associated with higher energy and fat intake. By contrast, in normal-weight people, snacking does not necessarily lead to increased energy intake, while snacks often contain more carbohydrates and less fat than regular meals. Obese people tend to eat little in the morning and much in the afternoon and the evening. In extreme cases, a "night-eating syndrome" is observed. Understanding the relationship between the circadian distribution of intake and obesity (or resistance to weight loss) seems critical for theoretical as well as clinical reasons.

Keywords: energy balance; meal pattern; snacking

\section{Introduction}

In human societies, eating is a patterned activity. Social constraints usually determine how many meals are to be ingested daily, and when meals are or are not appropriate. The meal pattern is an important aspect of social interactions. Just a few years ago, in many European societies, it was difficult, if not impossible, and most often considered inappropriate, to have food at other times than the socially accepted mealtimes. A newborn child was trained early to shape his or her eating behaviour according to the socially appropriate pattern. Clearly, this situation has changed in recent years in developed societies, where food has become available constantly and in practically unlimited amounts.

The development of the obesity epidemic has coincided with the loosening of traditional meal patterns, and it seems legitimate to ask whether this had any impact on the energy balance of individuals, and on their ability to control body weight. A lot of research has been devoted to the relationships

\footnotetext{
$\overline{{ }^{1} \text { Based }}$ on a lecture presented at a meeting arranged by the Swedish Nutrition Foundation in Stockholm, Sweden, March 11, 2004.
}

between the daily meal pattern and the body's adiposity status (1). Two important aspects of the meal pattern have been investigated: the daily meal number and the circadian distribution of intake.

\section{The daily meal number and body adiposity}

Is there an optimal number of daily eating occasions to facilitate body weight control? This question has drawn much interest since the 1950s, when observational and intervention studies suggested an inverse relationship between the daily meal number and body adiposity: a nibbling pattern was thought to be more favourable to low body mass than a gorging pattern, for a given energy intake. Work by Pavel Fabry and colleagues $(2,3)$ popularized the notion that eating often was associated with lower body fatness in middle-aged men as well as in schoolchildren. A number of observational studies produced congruent results in the following years (4-6).

Over the same period, investigators became increasingly suspicious of self-reported food intake data. Dietary underreporting by overweight people has been increasingly recognized as a strong confounding factor in epidemiological studies (7-9). Underreporting affects not only energy intake, but 
also the daily number of eating occasions, and snacks are particularly prone to underreporting (10-12). The development of the doubly labelled water technique to measure body energy expenditures made it clear to the scientific community that a certain level of underreporting of food intake occurred in the population at large (about 20\%) and that underreporting was likely to be aggravated in overweight and obese subjects (some people underreported their energy intake by $50 \%$ or even more) $(9,13)$. Such observations cast doubt on the validity of data suggesting that heavy people eat fewer meals a day than their leaner peers. In a study by Kant (5), the results again suggested that lower body mass index (BMI) was associated with increasing daily meal number, but also made it clear that the heaviest subjects, who reported fewer meals, also reported total energy intakes that were totally incompatible with their minimal energy needs.

Later studies comparing nibbling and gorging meal patterns were more prudent about potential underreporting and found no significant differences in body adiposity as a function of daily meal number (14-17). A recent study even reported more daily meals in obese than in lean women (18). Recently, Ma et al. (19) found a significant decrease in the risk of obesity with increasing meal number, but again the potential impact of underreporting in this study could be important.

What mechanisms could allow a nibbling meal pattern to induce less body fat accumulation than a gorging pattern? Two types of effect have been investigated. Several studies assessed the postprandial energy expenditure (the thermic effect of feeding), using a ventilated hood technique (20-24). The results of these studies are inconsistent. While half find non-significant differences between one daily meal and two or four meals, others report either a higher thermic effect with gorging than with nibbling, or the opposite. Other studies have investigated the total daily energy expenditure on nibbling versus gorging patterns using whole-body calorimetry: all reported non-significant differences (25-28). One study used the doubly labelled water method and again reported no difference in total daily energy expenditure as a function of daily meal number (27).

The potential benefits of a nibbling versus a gorging meal pattern for body weight loss were investigated in obese patients. While one study suggested that weight loss induced by a low-calorie diet might be facilitated on seven rather than three meals a day (29), several other studies failed to demonstrate any effects on the amount or rate of weight loss attributable to meal number, when energy intake was held constant $(27,30-33)$.

In conclusion, the early suggestion of an inverse relationship between daily meal number and body adiposity has not been confirmed. This notion probably resulted from underreporting of food intake by the heavier participants in observational studies. In addition, no mechanism has been found to account for any potential benefit of nibbling versus gorging on body fat accumulation: total daily energy expenditure is the same on both types of meal pattern. During a low-calorie diet, all other things being equal, meal number has no demonstrated effect on the amount or the rate of weight loss.

Under controlled laboratory or hospital conditions, it is possible to determine patients' or subjects' daily energy intake and to distribute it over a certain number of eating occasions. In freeliving conditions, however, the daily energy intake is not limited by clinical or experimental control, and a higher daily meal number may be a potential cause of overeating in many obese individuals with satiety deficits, who experience great difficulty in terminating a meal once they have started eating.

\section{Snacking}

Until recently, many European societies maintained a traditional meal pattern and it was inappropriate for adults to consume foods at other times than socially accepted mealtimes. Some tolerance was granted for children, but they were strongly encouraged to adopt the adult meal pattern as early as possible. This situation has changed enormously in recent years. Adults and children can obtain food at any time and usually do not even question the appropriateness of snacking between meals. Such trends have been revealed by recent epidemiological studies in France (34) and Sweden (18), for example.

In France, a recent study of adults showed that most people snack at least once almost every day (35). Snacking can occur at any time of day (morning, afternoon, evening). In these healthy, non-obese subjects, days without snacks resulted in the same amount of energy as days with snacks, suggesting some form of energy compensation. This observation agrees with numerous reports from other countries (36-38). It has often been reported that in healthy individuals, snacks contain a higher proportion of carbohydrates and a smaller proportion of fats than 
meals $(35,39-41)$. Thus, snacking in healthy people apparently improves the nutrient content of the diet without adding energy to it. Could the influence of snacking be different in obese people?

Snacking is generally held to exert a deleterious influence on the development and/or maintenance of obesity. In 1988, Booth stated that the "growing trend for 'grazing' rather than of the traditional pattern of three proper meals a day is a major factor in the aetiology of obesity" (42). Many studies have lent support for this notion. For example, Bertéus Forslund et al. (18) showed that obese Swedish women snack more often and have higher energy intake than lean peers. In obese French women, snackers have a higher energy intake than non-snackers (43).

Snacking thus appears to have more complex effects than was thought just a few years ago. Snacking may not always be the deleterious, unhealthy behaviour that it has often been considered to be. Indeed, very active people (children as well as adults) snack often but are leaner than less active peers. Very active children (44) often snack on healthy carbohydrate- or protein-rich foods. Therefore, snacking can contribute to improve the nutrient balance in some people, but may be deleterious in others (people with weight-control problems or satiety deficit, lovers of high-fat, highsugar foods, etc.).

\section{Circadian distribution of intake}

In spite of years of dedicated research, it has never been possible to identify a single behavioural characteristic that would be specific to the obese population as a whole. There is, however, one very consistent finding that has been reported in several comparisons of obese and normal weight peers: obese people tend to eat less in the morning than lean controls, and to eat more in the afternoon and evening. In other words, the circadian distribution of daily intake consistently appears different in obese versus nonobese individuals. This has been reported in children (45), adolescents (46) and adults $(18,47)$. One exception to this general finding was that Andersson and Rössner (17) did not report any difference in the daily distribution of intake events between normalweight and obese Swedish men.

A dietary survey showed that the body weight status in French children was associated with a different distribution of daily energy over the various daily eating occasions: a higher percentage of daily energy was ingested at breakfast in lean and medium-weight French children, while dinner brought a higher proportion of daily energy in overweight and obese children (45). A recent study of Swedish women showed that all types of eating event (meals and snacks) were more numerous in obese than in control women (18), an effect accounted for by the more frequent eating occasions reported in the afternoon and evening, between traditional mealtimes.

It is not known whether this peculiar daily distribution of eating is a cause or a consequence of the obese status. How could eating late in the day contribute to obesity? It may be easier to adjust intake to needs if intake is more evenly distributed over the waking hours, so that intense sensations of hunger are not allowed to develop between intakes. In addition, it has been shown that the ingestion of breakfast is associated with better nutrient content of the diet and less snacking later in the day, which again may help to limit total energy intake. Conversely, skipping breakfast has been associated with unplanned overeating later in the day, due to intense hunger, more precisely with the ingestion of highfat, high-sugar snacks (48). In extreme cases, the tendency to eat late in the day may lead to the "night-eating syndrome", originally described by Stunkard et al (49). This cluster of obesity-linked behaviours (although it can also be found in nonobese patients) includes night eating, insomnia and morning anorexia (50).

A recent study of 867 healthy adults (36.3-yearold, BMI 24.5 on average) who filled out 7 day diet diaries established that the proportion of daily intake ingested in the morning correlates negatively with total daily energy intake, while the proportion ingested late in the day correlates positively with overall energy intake (51). In other words, people who eat early eat less, while people who eat late eat more. The larger total intake of late eaters could contribute to the development of obesity.

During a 9 month weight-loss programme, carried out over a school year, massively obese adolescents were exposed to a low-fat reducing diet distributed over three daily meals (including breakfast) plus one afternoon snack (52). The diet breakfast brought $20 \%$ of the daily energy. After the end of the diet and a substantial weight loss, the participants returned to their homes and usual activities. Follow-up investigations carried out 1 and 2 years after the end of the weight-loss programme showed that while body weight was 
being regained progressively, the daily meal pattern had altered: breakfast tended to return to prediet energy content and extraprandial snacking increased, especially in the afternoon and evening. So, independently of actual daily energy intake, meal pattern changed during the weight regain period and this change was in the direction of a return to the pretreatment obese meal pattern. Such resistance to behavioural change suggests that a strong mechanism is working to reinstate the "obese meal pattern", independently of energy intake. The obese meal pattern could be causally related to the development or maintenance of obesity; however, the exact nature of the underlying mechanism remains unknown.

\section{Conclusion}

There is no clear, consistent evidence linking daily number of eating occasions and body adiposity. While traditional eating patterns are likely to change as a result of to present-day living conditions, the presence of snacking in the diet should be evaluated in terms of both energy and nutrient contributions. Understanding the relationship between the circadian distribution of daily intake and body adiposity status appears to be a critical issue for the prevention and treatment of obesity.

\section{References}

1. Bellisle F, McDevitt R, Prentice AM. Meal frequency and energy balance. Br J Nutr 1997; 77 Suppl 1: S57-70.

2. Fabry P, Fodor J, Heijl Z, Braun T, Zvolankova K. The frequency of meals: its relation to overweight, hypercholesterolaemia, and decreased glucose tolerance. Lancet 1964; ii: 614-5.

3. Fabry P, Hejda S, Cerna K, Osancova K, Pechor J, Zvolankova K. Effect of meal frequency in schoolchildren: changes in weight-height proportion and skinfold thickness. Am J Clin Nutr 1966; 18: 358-61.

4. Charzewska J, Kulesza W, Brzezinska J, Chwojnowska Z. Relationship between obesity or overweight development and the frequency of meals, their distribution during the day and consumption of atherogenic food products. Zywienie Czlowieka 1981; 8: 217-27.

5. Kant AK. Frequency of eating occasions and weight changes in NHANES I epidemiologic follow-up study. Int J Obes 1995; 19: 468-74.

6. Prentice AM, Black AE, Coward WA, Davies HL, Goldberg GR, Murgatroyd PR, et al. High levels of energy expenditure in obese women. Br Med J 1986; 292 : 983-7.

7. Lichtman SW, Pisarska K, Berman ER, Pestone H, Dowling H, Offenbacker E, et al. Discrepancy between self-reported and actual caloric intake and exercise in obese subjects. N Engl J Med 1992; 327: 1893-8.

8. Black AE, Prentice AM, Goldberg GR, Jebb SA, Bingham SA, Livingstone MB, et al. Measurements of total energy expenditure provide insights into the validity of dietary measurements of energy intake. J Am Diet Assoc 1993; 93: 572-9.

9. Metzner HL, Lamphiear DE, Wheeler NC, Larkin FA. The relationship between frequency of eating and adiposity in adult men and women in the Tecumseh Community Health Study. Am J Clin Nutr 1977; 30: 712-5.

10. Livingtone MBE, Prendice AM, Strain JJ, Coward WA, Black AE, Barker ME, et al. Accuracy of weighted dietary records in studies of diet and health. Br Med J 1990; 300: 708-12.

11. Heitmann BL, Lissner L. Dietary underreporting by obese individuals - is it specific or non-specific? Br Med J 1995; 311: 986-9.

12. Poppitt SD, Swann D, Black AE, Prentice AM. Is under-reporting of energy intake in obese women macronutrient specific? Covert measurements in a metabolic facility. Int J Obes 1995; 19 Suppl 2: 983-7.

13. Schoeller DA. Limitations in the assessment of dietary energy intake by self-report. Metabolism 1995; 44: 1822.

14. Dreon DM, Frey-Hewitt B, Ellsworth N, Williams PT, Terry EB, Wood PD. Dietary fat:carbohydrate ratio and obesity in middle-aged men. Am J Clin Nutr 1988; 47: 995-1000.

15. Edelstein SL, Barrett-Connor EL, Wingard DL, Cohn BA. Increased meal frequency associated with decreased cholesterol concentrations; Rancho Bernardo CA, 1984-1987. Am J Clin Nutr 1984; 55: 664-9.

16. Summerbell CD, Moody RC, Shanks J, Stock MJ, Geissler C. Relationship between feeding pattern and body mass index in 220 free-living people in four age groups. Eur J Clin Nutr 1996; 50: 513-9.

17. Andersson I, Rössner S. Meal patterns in obese and normal weight men: the "Gustaf" study. Eur J Clin Nutr 1996; 50: 639-46.

18. Bertéus Forslund H, Lindroos AK, Sjöstrom L, Lissner L. Meal patterns and obesity in Swedish women - a simple instrument describing usual meal types, frequency and temporal distribution. Eur $\mathbf{J}$ Clin Nutr 2002; 56: 740-7.

19. Ma Y, Bertone ER, Stanek EJ III, Reed GW, Hebert JR, Cohen NL, Merriam PA, et al. Association between eating patterns and obesity in a free-living US adult population. Am J Epidemiol 2003; 158: 85-92.

20. Belko AZ, Barbieri TF. Effect of meal size and frequency on the thermic effect of food. Nutr Res 1987; 7: 237-42.

21. Kinabo JLD, Durnin JVGA. Effect of meal frequency on the thermic effect of food in women. Eur J Clin Nutr 1990; 44: 389-95.

22. Molnar D. The effect of meal frequency on postprandial thermogenesis in obese children. Padiatrie Padologi 1992; 27: 177-81. 
23. Tai MM, Castillo P, Pi-Sunyer FX. Meal size and frequency: effect on the thermic effect of food. Am J Clin Nutr 1991; 54: 783-7.

24. Le Blanc J, Mercier I, Nadeau A. Components of postprandial thermogenesis in relation to meal frequency in humans. Can J Physiol Pharmacol 1993; 71: 879-83.

25. Dalosso H, Murgatroyd PR, James WPT. Feeding frequency and energy balance in adult males. Hum Nutr Clin Nutr 1982; 36C: 25-39.

26. Wolfram G, Kirchbegner M, Müller HL, Hollomey S. Thermegenese des Menschen bei unterschiedlicher Malzeitenhäufigkeit (Thermogenesis in human subjects with differing meal frequencies). Ann Nutr Metab 1987; 31: 88-97.

27. Verboeket-van de Venne WPHG, Westerterp KR. Frequency of feeding, weight reduction and energy metabolism. Int J Obes 1993; 17: 31-6.

28. Taylor MA, Garrow JS. Compared with nibbling, neither gorging nor a morning fast affect short-term energy balance in obese patients in a chamber calorimeter. Int J Obes Relat Metab Disord 2001; 25: 519-28.

29. Debry G, Azouaou R, Vassilitch I, Mottaz G. Ponderal losses in obese subjects submitted to restricted diets differing by nibbling and by lipid and carbohydrate. Energy balance in man. Paris: Masson; 1973. p. 305-10.

30. Bortz WM, Wroden A, Issekortz B, Rodahl K. Weight loss and frequency of eating. N Engl J Med 1966; 27: 376-9.

31. Finkelstein B, Fryer BA. Meal frequency and weight reduction of young women. Am J Clin Nutr 1971; 24: 465-8.

32. Young CM, Scanlon SS, Topping CM, Simko V, Lutwak L. Frequency of feeding, weight reduction and body composition. J Am Diet Assoc 1971; 59: 466-72.

33. Garrow JS, Durrant M, Blaza S, Wilkins D, Royston P, Sunkin S. The effect of meal frequency and protein concentration on the compostion of the weight lost by obese subjects. Br J Nutr 1981; 45: 5-15.

34. Volatier JL. "Enquête INCA individuelle et nationale sur les consommations alimentaires" Paris: Lavoisier; 2000 .

35. Bellisle F, Dalix AM, Mennen L, Galan P, Hercberg S, de Castro JM, et al. Contribution of snacks and meals in the diet of French adults: a diet-diary study. Physiol Behav 2003; 79: 183-9.

36. Lawton CL, Delargy HJ, Smith FC, Hamilton V, Blundell JE. A medium-term intervention study on the impact of high- and low-snacks varying in sweetness and fat content: large shifts in daily fat intake but good compensation for daily energy intake. Br J Nutr 1998; 80: 149-61.

37. Johnstone AM, Shannon E, Whybrow, Reid CA, Stubbs RJ. Altering the temporal distribution of energy intake with isoenergetically dense foods given as snacks does not affect total energy intake in normal-weight men. $\mathrm{Br}$ J Nutr 2000; 83: 7-14.
38. King S, Gibney M. Dietary advice to reduce fat intake is more successful when it does not restrict habitual eating patterns. J Am Diet Assoc 1999; 99: 685-9.

39. Ballard-Barbash R, Thompson FE, Graubard BI, Krebs-Smith SM. Variability in percent energy from fat throughout the day: implications for application of total diet goals. J Nutr Educ 1994; 26: 278-83.

40. Summerbell CD, Moody RC, Shanks J, Stock MJ, Geissler C. Sources of energy from meals versus snacks in 220 people in four age groups. Eur J Clin Nutr 1995; 49: $33-41$

41. Drummond S, Crombie N, Kirk TA. A critique of the effect of snacking on body weight status. Eur J Clin Nutr 1996; 12: 779-83.

42. Booth DA. Mechanisms from models - actual effects from real life: the zero calorie drink-break option. Appetite 1988; 11: 94-102.

43. Basdevant A, Craplet C, Guy-Grand B. Snacking patterns in obese French women. Appetite 1993; 21: $17-23$.

44. Deheeger M, Rolland-Cachera MF, Fontvieille AM. Physical activity and body composition in 10 year old French children: linkages with nutritional intake? Int $\mathbf{J}$ Obes Relat Metab Disord 1997; 21: 372-9.

45. Bellisle F, Rolland-Cachera MF, Deheeger M, GuilloudBataille M. Obesity and food intake in children: evidence for a role of metabolic and/or behavioural daily rhythms. Appetite 1988; 11: 111-8.

46. Berkey CS, Rockett HRH, Gillman MW, Field AE, Colditz GA. Longitudinal study of skipping breakfast and weight change in adolescents. Int J Obes 2003; 27: 1258-66.

47. Fricker J, Giroux S, Fumeron F, Apfelbaum M. Circadian rhythm of energy intake and corpulence status in adults. Int $\mathrm{J}$ Obes 1990; 14: 387-93.

48. Schlundt DG, Hill JO, Sbrocco T, Pope-Cordle, Sharp T. The role of breakfast in the treatment of obesity: a randomized clinical trial. Am J Clin Nutr 1992; 55: 645 51 .

49. Stunkard AJ, Grace WJ, Wolff HG. The night-eating syndrome. A pattern of food intake among certain obese patients. Am J Med 1955; 19: 78-86.

50. Stunkard AJ, Berkowitz R, Wadden T, Tanrikut C, Reiss E, Young L. Binge-eating disorder and the night-eating syndrome. Int J Obes Relat Metab Disord 1996; 20: 1-6.

51. de Castro JM. The time of day of food intake influences overall intake in humans. J Nutr 2004; 134: 104-11.

52. Rolland-Cachera MF, Thibault H, Souberbielle JC, Soulié D, Carbonel P, Deheeger M, et al. Massive obesity in adolescents: dietary interventions and behaviours associated with weight regain at 2 years followup. Int J Obes Relat Metab Disord 2004; 28: 514-9.

\section{France Bellisle,}

INRA (National Institute of Agronomy), Hôtel-Dieu,

I Place du Parvis Notre-Dame, FR-75004 Paris, France

E-mail: f.bellisle@wanadoo.fr 